
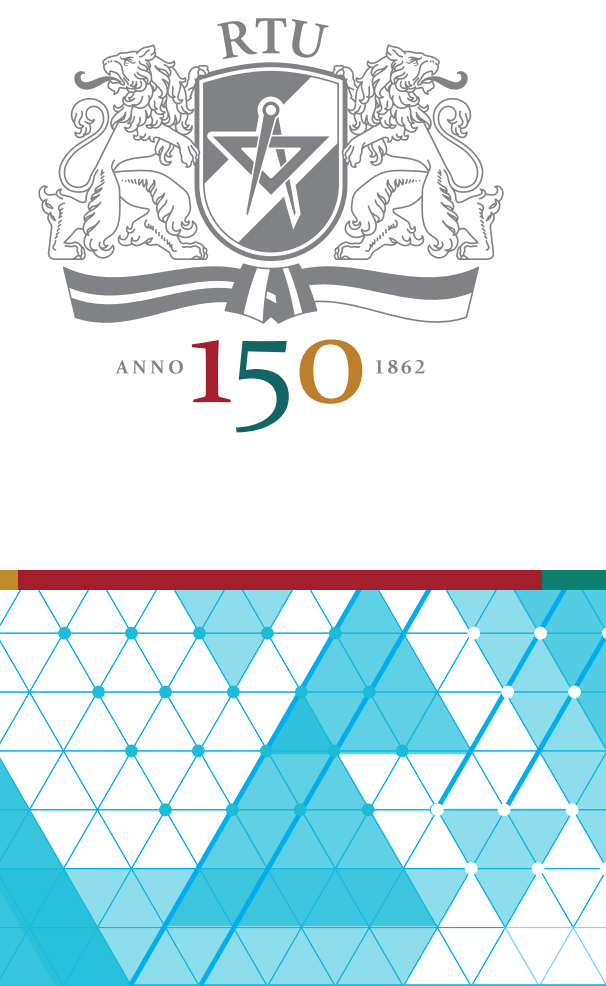

11-12 October 2012, Riga

Riga Technical University 53rd International Scientific Conference

Dedicated to the $150^{\text {th }}$ Anniversary and The 1 st Congress of World Engineers and Riga Polytechnical Institute / RTU Alumni

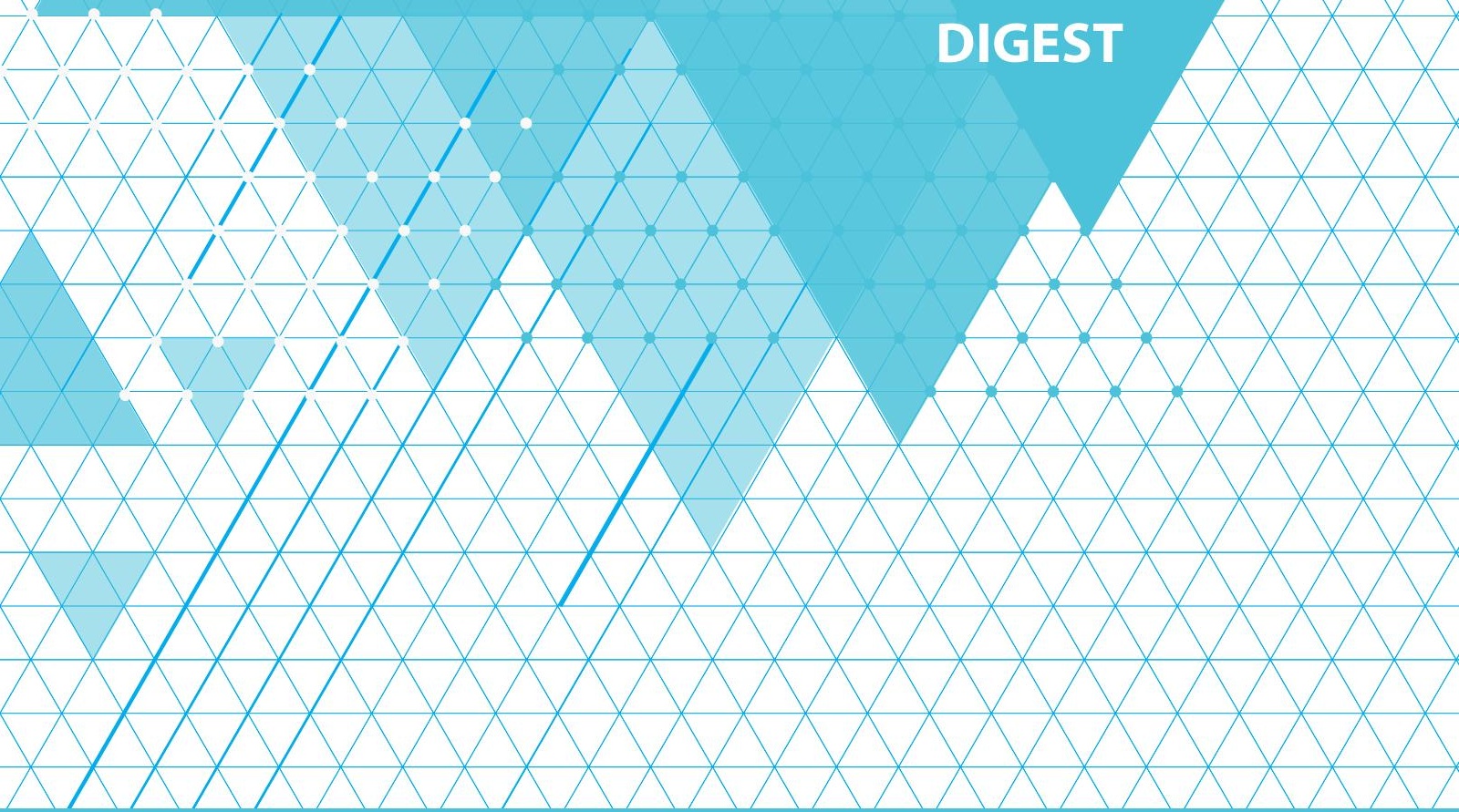




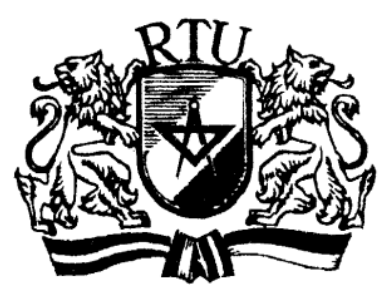

\section{RIGA TECHINICAL UNIVERSITY $53^{\text {rd }}$ INTERNATIONAL SCIENTIFIC CONFERENCE DEDICATED TO THE $150^{\text {th }}$ ANNIVERSARY AND THE $1^{\text {st }}$ CONGRESS OF WORLD ENGINEERS AND RIGA POLYTECHINICAL INSTITUTE / RTU ALUMINI}

11-12 October 2012

Rīga, Latvija 


\title{
Approach to the Silicon Sensor with Pre-threshold Electron Emission Readout to Detect Exhaled Breath Gases
}

\author{
Yuri Dekhtyar, Kristine Perovicha and Alexander Soudnikovich (RTU, Biomedical Engineering and \\ Nanotechnologies Institute )
}

Keywords - exhaled breath gas, silicon gas detector, electron emission.

\section{INTRODUCTION}

Preliminary diagnosis of human diseases such as cancer and diabetes is possible via the detection of violate organic compounds (VOCs) contained in exhaled breath gases. A pre-threshold electron emission yield from a solid emitter depends on the gas molecules adhered to the emitter, if the electron work function is influenced.

Since detecting techniques typically consist of a VOCs detector and equipment to amplify and record signal, there are two ways to enhance sensitivity: improving the detector and advance quality of the equipment.

The latter is boosted because of signal processing algorithms and circuitry decisions improvement. However, to get a better detector, the derivation of the signal (S) supplied by the detector on the VOCs concentration (C) is the most important option. The function $\mathrm{S}(\mathrm{C})$ could be written as:

$$
S(C)=S\left(C_{0}\right)+\left(C-C_{0}\right) \frac{d s}{d C}+\left(C-C_{0}\right)^{2} \frac{d^{2} s}{d c^{2}}+\cdots
$$

(1)

$C_{0}-$ value of $\mathrm{C}$ at that vicinity that $\mathrm{S}$ is derived.

The accuracy of $\mathrm{S}(\mathrm{C})$ is high when the nonlinear elements of the formula are kept. This can be achieved when the highly indexed derivations provide significant impact even when the difference $\left(C-C_{0}\right)$ is small. Such the conditions are available if the VOCs detector demonstrates nonlinear, preferably parabolic, dependence $\mathrm{S}$ on $\mathrm{C}$. The pre-threshold emission of electrons gives such a property.

Photoelectron emission (PE) current density (I) generally obeys the equation:

$\mathrm{I}=\mathrm{A}(\mathrm{h} v-\varphi)^{\mathrm{m}}$

$A$ - coefficient of proportionality, $h v$ - energy of the photon that excites the electron $[\mathrm{eV}], m$-coefficient that deals with transitions between the initial and final states of the electron, $m>1[4], \varphi$ - electron work function.

If the emitter attaches electrically active molecules, the value of $\varphi$ depends on their concentration. At the first approach:

$\varphi(C)=\varphi(C=0)+\Delta \varphi(C)$.

(3)

$\Delta \varphi(C)$ - the increment of $\varphi$ resulting from $\mathrm{C}$,

$\Delta \varphi(C)=\frac{\Delta \sigma(c) i}{2 \varepsilon \varepsilon_{0}}$,

(4)

$\Delta \sigma$ - surface charge density increment, influenced by C, $l-$ emitting electron main free path within the emitter, $\varepsilon$ electrical permittivity of the matter that the electron escapes from, $\varepsilon_{0}$ - electrical permittivity of vacuum.

Because of the above, $I$ is a parabolic $(m>1)$ function of $\mathrm{C}$ and I fits in (1). However to get the $\Delta \varphi$ response on $\mathrm{C}$, the value of $\varepsilon$ should not be large.
The alteration of $\varphi$ can also give a contribution to the weak thermoelectron emission (TE). Its electron current density $\mathrm{I}_{\mathrm{T}}$ obeys Richardson - Dushman formula:

$I_{T}(C)=B \cdot T^{2} \cdot \exp \left(\frac{-\varphi(C)}{k T}\right)$

$B$ - coefficient, $k$ - Boltzmann constant, $T$ - temperature K.

To prove this theory, the crystalline silicon ( $\mathrm{Si}$ ) specimens having $\mathrm{n}$ - and $\mathrm{p}$ - type conductivity were selected for the experiments (Table 1). This in addition to the above was motivated because:

- the PE of $\mathrm{Si}$ is provided due to indirect photoinduced electron transitions, $\mathrm{m}=2.5$ [1].

- the value of $\varepsilon$ is small, $\varepsilon=11.9$ [2].

Table 1 Electrical RESistance OF THE Si SPECIMENS

\begin{tabular}{ll}
\hline Type & Electrical resistance, $\Omega \cdot \mathrm{cm}$ \\
p-Si, doped with Boron (SHB) & 0.0005 \\
& 1 \\
\hline n-Si, doped with Phosphorus (SEP) & 0.0014 \\
& 5 \\
\hline
\end{tabular}

The gases of benzene (dipole moment $\mathrm{D}=0 \mathrm{D}$ [3]) and isopentane (dipole moment $\mathrm{D}=0.29 \mathrm{D}$ ) were selected as examples that are typical of lung cancer patients.

As the visual result using PE and TE, the differences of the measured emission currents densities before and after exposure were measured for the different $\mathrm{Si}$ types with benzene and isopentane gases.

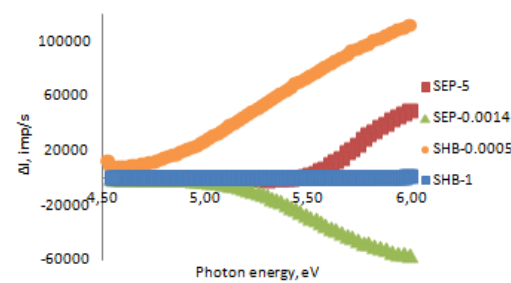

Fig. $1 \Delta \mathrm{I}$ of $\mathrm{PE}$ in bezene, exposure time $30 \mathrm{~min}$

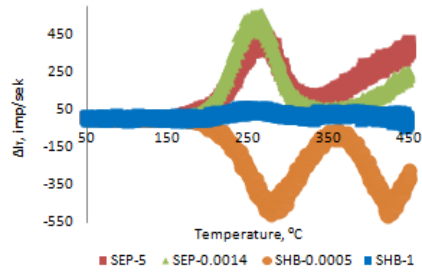

Fig. $3 \Delta \mathrm{I}_{\mathrm{T}}$ of TE in benzene, exposure time $30 \mathrm{~min}$.

\section{REFERENCES}

[1] Akmene R J, Balodis A J, Dekhtyar Yu D, Markelova G N, Matvejevs J V, Rozenfelds L B, Sagalovičs G L, Smirnovs J S, Tolkačovs A A and Upmiņš A I (1993) Exoelectron emission spectrometer complete set of surface local investigation. Poverhnost, Fizika, Himija, Mehanika 8:125

[2] Kane E (1962) Theory of photoelectric emission from semiconductor ctors. Phys Rev 127:131-141

[3] Benzene at http://en.wikipedia.org/wiki/Benzene, 30.04.2012 